\title{
AMCoR
}

Asahikawa Medical University Repository http://amcor.asahikawa-med.ac.jp/

Parasitology International (2010) 59(2):268-270.

Anomalous segmentation of Diphyllobothrium nihonkaiense

Yanagida, Tetsuya ; Matsuoka, Hiroyuki ; Kanai, Takahiro ; Nakao, Minoru ; Ito, Akira 


\section{Anomalous segmentation of Diphyllobothrium nihonkaiense}

Tetsuya Yanagida ${ }^{1}$, Hiroyuki Matsuoka ${ }^{2}$, Takahiro Kanai ${ }^{3}$, Minoru Nakao ${ }^{1}$, Akira Ito ${ }^{1}$

${ }^{1}$ Department of Parasitology, Asahikawa Medical College, Asahikawa, Hokkaido 078-8510, Japan

${ }^{2}$ Division of Medical Zoology, Department of Infection and Immunity, Jichi Medical University, Yakushiji 3311-1, Shimotsuke, Tochigi 329-0498, Japan

${ }^{3}$ Department of Pediatrics, Jichi Medical University, Yakushiji 3311-1, Shimotsuke, Tochigi 329-0498, Japan

*Corresponding author. Department of Parasitology, Asahikawa Medical College, Asahikawa, Hokkaido 078-8510, Japan.

Tel. $+81-166-68-2421$

Fax. $+81-166-68-2429$

E-mail address: yanagida@asahikawa-med.ac.jp

Nucleotide sequences determined in this report were deposited into DDBJ/EMBL/GenBank databases under the accession numbers of AB512013 (18S rDNA), AB508837 (cob) and AB508838 (cox1).

\section{Abstract}


An anomalous tapeworm with abnormal segmentation was obtained from 6-year-old boy in Japan. The tapeworm consisted of proglottids with slanted anterior and posterior margins of proglottids and 4-6 sets of reproductive organs arranged between the margins. The morphology of the tapeworm did not correspond to any of the described cestodes. However, molecular identification based on nuclear and mitochondrial genes clearly showed the tapeworm was Diphyllobothrium nihonkaiense.

Key words:

Diphyllobothrium nihonkaiense

Anomalous segmentation

Molecular identification 
Human diphyllobothriasis spreading worldwide, is a cestode zoonosis caused by eating raw or undercooked fish infected with larvae of Diphyllobothrium spp. (Diphyllobothriidae)[1, 2]. There are more than 10 species known to cause human infection [1, 3]. The main pathogenic organism is Diphyllobothrium nihonkaiense in Japan [4, 5], while Diphyllobothrium latum is common in European countries [6]. D. nihonkaiense had been considered as the same species with D. latum until 1986, when Yamane et al. [7] differentiated the both species. Although those tapeworms are morphologically similar to each other, their second intermediate hosts are crucially different. D. nihonkaiense exploits anadromous Pacific salmons such as Oncorhynchus masou masou (masu salmon), Oncorhynchus gorbuscha (pink salmon) and Oncorhynchus keta (chum salmon), whereas D. latum exploits freshwater fish such as Perca fluviatilis (perch) and Esox lucius (pike). Another tapeworm Diplogonoporus balaenopterae belonging to the family Diphyllobothriidae also causes intestinal infections in Japan [8, 9]. The most crucial morphological difference between the genera Diphyllobothrium and Diplogonoporus is the number of genitalia per segment. Except for the abnormal development of the strobila, Diphyllobothrium spp. have a single set of genitalia, whereas Diplogonoporus spp. have double sets.

Species identification of these tapeworms has been basically based on the morphology of larval and adult stages. However, the morphological 
identification is little reliable, particularly in sibling species and atypical individuals. Therefore, molecular diagnostic tools using mitochondrial DNA (mtDNA) and nuclear DNA markers have been widely utilized for the identification of tapeworms [10-16]. Here we report a clinical case infected with an abnormal tapeworm, which was later identified as D. nihonkaiense by molecular diagnosis.

A 6-year-old boy, living in Oyama City, Tochigi Prefecture, shed a tapeworm for the first time on January 2008, and was referred to Jichi Medical University Hospital on September 3 but without specimen. No treatment was done at that time. Next time, he came on October 24, 2008 with a newly expelled worm specimen with $40 \mathrm{~cm}$ of length. He had not been claiming any subjective symptom other than releasing worms. Three weeks later, the patient was treated with praziquantel and laxative. We examined the patient's feces for 2 days and the tapeworm was only found in the feces obtained 24 hours after the treatment. Because the tapeworm was considerably damaged and fragmented in much feces, the scolex part was unfortunately not found after all. Although the scolex was not found after the treatment, the whole tapeworm was considered to be released because the obtained mass of proglottids contained a narrow part close to the neck region.

The tapeworm consisted of only abnormal proglottids throughout the obtained strobila (Fig. 1A). Eggs found in the feces of the patient resembled 
the eggs of Diphyllobothrium. The worm obtained in October was fixed with $70 \%$ ethanol, and morphological observation and molecular diagnosis were conducted at Asahikawa Medical College. A part of the strobila was whole-mounted and stained with Semichon's acetic carmine. Some parts were embedded in paraffin, cut into $5 \mu \mathrm{m}$ and stained with hematoxylin and eosin. Another part was refixed with $2.5 \%$ glutaraldehyde and used for scanning electron microscope (SEM) observation.

The width of the strobila was about $1 \mathrm{~cm}$, and a maximum thickness was $650 \mu \mathrm{m}$ (Fig. 1A, B). Margins of proglottids slanted to left both on the ventral and dorsal side. From the frontal view, 4-6 sets of reproductive organs were arranged between the anterior and posterior margins of proglottids (Fig. 1A, C). Some of the uteri contained eggs. SEM observation revealed the genital pores opened only on the ventral surface (data not shown). The eggs had an operculum at one end and an apical knob at the other. The size of the eggs $(n=20)$ were $67.6(61.8-73.8) \times 45.1(42.4-$ 48.1) $\mu \mathrm{m}$ (Fig. 1D).

The parasite DNA was extracted with DNeasy Blood \& Tissue Kit (Qiagen), and the nuclear DNA fragment of $18 \mathrm{~S}$ ribosomal RNA gene (18S rDNA) was amplified by polymerase chain reaction (PCR) using the universal eukaryotic primers ERIB1 (5'-acctggttgatcctgccag-3') and ERIB10 (5'-cttccgcaggttcacctacgg-3') [17]. The mtDNA fragments of cytochrome $c$ oxidase subunit I (cox1) and cytochrome $b$ (cob) were also 
amplified with two sets of primers; Diphyllo-Cox1-F/R (5'-tagactaagtgtttcaaaacacta-3'/5' -atagcatgatgcaaaagg-3') and Diphyllo-Cob-F/R (5'-tgataggttatttaaactggc-3'/5'-tcaacagttgaaacaacca). All PCRs were performed in $20 \mu \mathrm{L}$ volumes containing 0.5 units of Ex Taq (Hot Start Version $($ TaKaRa), $0.2 \mathrm{mM}$ of dNTP, $1 \times$ Ex Taq Buffer with a final $\mathrm{MgCl}_{2}$ concentration of $2.0 \mathrm{mM}, 15 \mathrm{pmol}$ of each primer and $1.0 \mu \mathrm{L}$ of genomic DNA. Main thermal reactions were performed as follows; 35 cycles of $94^{\circ} \mathrm{C}$ for $30 \mathrm{~s}, 55^{\circ} \mathrm{C}$ for $30 \mathrm{~s}$ and $72^{\circ} \mathrm{C}$ for $60 \mathrm{~s}(\operatorname{cox} 1$ and cob), and 35 cycles of $95^{\circ} \mathrm{C}$ for $1 \mathrm{~min}, 54^{\circ} \mathrm{C}$ for $1 \mathrm{~min}$ and $72^{\circ} \mathrm{C}$ for $2 \min (18 \mathrm{~S} \mathrm{rDNA})$. A BigDye $\mathrm{BM}^{\mathrm{TM}}$ Terminator $\mathrm{v} 1.1$ and a 310 DNA sequencer (Applied Biosystems) were used for the direct sequencing of the PCR products.

The partial sequence of $18 \mathrm{~S}$ rDNA (2134 bp) and the complete sequences of cob (1107 bp) and cox1 (1566 bp) were determined and compared with available sequences in the GenBank database. The $18 \mathrm{~S}$ rDNA sequence was completely identical with that of D. nihonkaiense (AB374225). Both cob and cox1 sequence showed more than $99.5 \%$ identities with those of D. nihonkaiense (EF420138), whereas the similarities of the cox1 sequence with D. dendriticum (AM412738) and D. latum (FM209181) were 93.2\% and 92.6\%, respectively.

Morphologically, the most notable feature of the strange worm was the slanted anterior and posterior margins of proglottids. Because the margins of proglottids on the ventral and dorsal tegument were not parallel to each 
other, the tapeworm was considered not to have "segments" in a usual meaning. Another feature of the tapeworm was multiple sets of reproductive organs arranged between the anterior and posterior margins of proglottids. Although the worm was thought to be a member of the genus Diphyllobothrium or Diplogonoporus because of the egg morphology, there was no described species having such a strange strobila. While morphological observation did not identify the species, 18S rDNA, cox1 and cob sequences of the parasite showed high similarity to that of $D$. nihonkaiense. $18 \mathrm{~S}$ rDNA is rather conservative and unsuitable for interspecific characterization among some Diphyllobothrium species such as D. latum, D. dendriticum and D. ditremum $[13,14]$. On the other hand, cox1 is more variable and can clearly discriminate those three species [13, 14]. Intraspecific mtDNA sequence divergence in D. nihonkaiense is relatively high, around $2 \%$ in $\operatorname{cox} 1$ and $\mathrm{NADH}$ dehydrogenase subunit 3 (nad3) $[10,11]$. The complete cox1 sequence of the tapeworm obtained in the present study showed $99.7 \%$ similarity with D. nihonkaiense. Thus, molecular analysis clearly showed that the strange tapeworm was an anomalous D. nihonkaiense. Occurrence of abnormal progrottids of $D$. nihonkaiense was intensively examined with 140 specimens preserved in 17 universities and research institutes in Japan, and many types of abnormal forms were recorded [18]. They were divided into 12 major types including that with 2-4 sets of genital organs per segments and/or abnormal 
segmentation. Koga and Iwata [18] found that the occurrence of abnormal forms of D. nihonkaiense was rather common. However, none of the abnormal types in the previous report was similar to the present case. Most of the cases in the previous report consisted of both normal and abnormal segments, whereas the specimen in the present case was composed of only abnormal forms throughout the obtained strobila. The cause and the mechanism of the occurrence of the abnormal proglottids in the diphyllobothriid cestodes are still unknown. Koga and Iwata [18] speculated that the abnormal forms, such as double sets of genitalia in one segment, show the progress of subdivision of the mature progrottids. On the other hand, Anderson [19] obtained abnormally large and slender plerocercoids of Diphyllobothrium dendriticum from rainbow trout Oncorhynchus mykiss experimentally infected by the intraperitoneal injection of plerocercoids with scolex removed. The author suggested the scolex or neck region control the growth and development of cestodes and the abnormal development would occur if those parts were removed. The abnormal segmentation in the present case was considered to have occurred not among the mature progrottids but in the scolex or neck region resulting from the failure of the regulation of developmental gene expression in early morphogenetic process, because the abnormal form appeared constantly in the specimen.

Retrospective interview with the patient could not find any history of 
eating raw or undercooked salmons, except for a grilled rainbow trout farmed in the river in Japan. Rainbow trout has not been reported as the host of D. nihonkaiense so far. Besides, extensive fieldwork on masu salmon, $O$. masou masou, in Hokkaido, the north island of Japan, revealed that the juveniles in the river before migrating to the sea were not infected with $D$. nihonkaiense, whereas the adults returned to the rivers had prevalences ranging from 0 to $50 \%$. It strongly suggests that $O$. masou masou acquires the parasite during their migration through the ocean [20]. It is, therefore, highly unlikely that the grilled rainbow trout was the source of infection. The origin of the strange D. nihonkaiense remains unknown. Until recently, D. nihonkaiense was considered to distribute only around Japan and Far East Russia. However, clinical cases of D. nihonkaiense have been reported in France, Switzerland, Canada and New Zealand in the past 5 years $[12,14$, $15,21,22]$. The authors of these reports suspected that the cases were caused by eating Pacific salmons imported from Pacific coast of North America, except for the case of a Czech tourist who ate 5 species of Pacific salmons in Canada [14]. These case reports indicate the expansion of $D$. nihonkaiense infection resulted from the worldwide transportation of fresh salmons, and a broader geographical distribution of the parasite than previously considered. However, D. nihonkaiense has not been confirmed from other than three species of Pacific salmons (O. masou masou, $O$. gorbuscha, O. keta) in Japan and Far East Russia so far. There has been no 
report of D. nihonkaiense larvae from any imported/exported Pacific salmons. To clarify the geographical distribution and the host range of $D$. nihonkaiense, more extensive fieldwork on Pacific salmons, especially along the Pacific coast of North America, is needed.

\section{Acknowledgement}

This study was supported in part by International Collaboration Research Fund from the Japan Society for the Promotion of Science (17256002, 21256003) to Akira Ito.

\section{References}

[1] Scholz T, Garcia HH, Kuchta R, Wicht B. Update on the human broad tapeworm (genus Diphyllobothrium), including clinical relevance. Clin Microbiol Rev 2009;22:146-60.

[2] Craig PS, Ito A. Intestinal cestodes. Cur Opinion Infect Dis 2007; 20:524-32.

[3] Kamo H. Guide to identification of diphyllobothriid cestodes. Gendai Kikaku: Tokyo, 1999. (in Japanese)

[4] Arizono N, Yamada M, Nakamura-Uchikawa F, Ohnishi K. Diphyllobothriasis associated with eating raw Pacific salmon. Emerg Infect Dis 2009;15:866-70.

[5] Matsuoka H, Yoshida S, Hirai M, Ishii A. Reports of parasitic diseases 
and entomological cases in the Department of Medical Zoology, Jichi Medical School: Accumulated cases from five years. Jpn J Infect Dis $2001 ; 54: 148-50$.

[6] Dupouy-Camet J, Peduzzi R. Current situation of human diphyllobothriasis in Europe. Euro Surveill 2004;9:31-4.

[7] Yamane Y, Kamo H, Bylund G, Wikgren BJ. Diphyllobothrium nihonkaiense sp. nov. (Cestoda: Diphyllobothriidae)-revised identification of Japanese broad tapeworm. Shimane J Med Sci 1986;10:29-48.

[8] Kamo H. Cestodes. Progress of medical Parasitology in Japan, vol. 8. Tokyo: Meguro Parasitological Museum Press; 2003. P. 235-43.

[9] Arizono N, Fukumoto S, Tademoto S, Yamada M, Uchikawa R, Tegoshi T, Kuramochi T. Diplogonoporiasis in Japan: Genetic analyses of five clinical isolates. Parasitol Int 2008;57:212-6.

[10] Nakao M, Davaajav A, Yamasaki H, Ito A. Mitochondrial genomes of the human broad tapeworms Diphyllobothrium latum and Diphyllobothrium nihonkaiense (Cestoda: Diphyllobothriidae). Parasitol Res 2007;101:233-6.

[11] Arizono N, Shedko M, Yamada M, Uchikawa R, Tegoshi T, Takeda K, Hashimoto K. Mitochondrial DNA divergence in populations of the tapeworm Diphyllobothrium nihonkaiense and its phylogenetic relationship with Diphyllobothrium klebanovskii. Parasitol Int 
$2009 ; 58: 22-8$.

[12] Wicht B, de Marval F, Peduzzi R. Diphyllobothrium nihonkaiense (Yamane et al., 1986) in Switzerland: first molecular evidence and case reports. Parasitol Int 2007;56:195-9.

[13] Wicht B, de Marval F, Gottstein B, Peduzzi R. Imported diphyllobothriasis in Switzerland: molecular evidence of Diphyllobothrium dendriticum (Nitzsch, 1824). Parasitol Res 2008;102:511-4.

[14] Wicht B, Scholz T, Peduzzi R, Kuchta R. First record of human infection with the tapeworm Diphyllobothrium nihonkaiense in North America. Am J Trop Med Hyg 2008;78:235-8.

[15] Yera H, Estran C, Delaunay P, Gari-Toussaint M, Dupouy-Camet J, Marty P. Putative Diphyllobothrium nihonkaiense acquired from Pacific salmon (Oncorhynchus keta) eaten in France; genomic identification and case report. Parasitol Int 2006;55:45-9.

[16] Dupouy-Camet J, Yera H. Diphyllobothrium. In: Liu D, editor. Molecular detection of foodborne pathogens. London: Taylor and Francis Group, 2009:781-8.

[17] Bartra JR, Martin DS, Liberator PA, Dashkevicz M, Anderson JW, Feighner SD, Elbrecht A, Parkins-Barrow A, Jenkins MC, Danforth HD, Ruff MD, Profousjuchelka H. Phylogenetic relationships among eight Eimeria species infecting domestic fowl inferred using complete small 
subunit ribosomal DNA sequences. J Parasitol 1997;83:262-71.

[18] Koga G, Iwata S. On the abnormal proglottids of broad tapeworm Diphyllobothrium latum (L., 1758) with a single or double sets of reproductive organs. J Kurume Med Assoc 1976;39:475-505. (in Japanese)

[19] Anderson K. Abnormal growth pattern of Diphyllobothrium dendriticum in rainbow trout. J Helminth 1979;53:39-40.

[20] Awakura T, Sakaguchi S, Hara T. Studies on parasites of masu salmon, Oncorhynchus masou - observations on the seasonal occurrence of Diphyllobothrium latum plerocercoid. Scientific Reports of the Hokkaido Fish Hatchery 1985;40:57-67. (in Japanese)

[21] Shimizu H, Kawakatsu H, Shimizu T, Yamada M, Tegoshi T, Uchikawa R, Arizono N. Diphyllobothriasis nihonkaiense: possibly acquired in Switzerland from imported Pacific salmon. Intern Med 2008;47:1359-62.

[22] Yamasaki H, Kuramochi T. A case of Diphyllobothrium nihonkaiense infection possibly linked to salmon consumption in New Zealand. Parasitol Res 2009; 105:583-6.

\section{Figure legend}

Fig. 1. The strobila and the egg obtained in the present case. (A) Whole-mounted specimen of the strobila with multiple reproductive organs. 
(B) Transverse section of the strobila stained with hematoxylin and eosin. Arrowheads show the margins. c: cirrus. cs: cirrus sac. u: uterus. Bar $=1$ mm. (C) Schematic diagram of the strobila. Solid lines and broken lines show anterior and posterior margins of proglottidsr respectively. (D) The egg with an apical knob. Bar $=20 \mu \mathrm{m}$. 